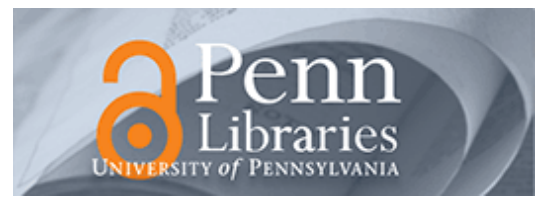

University of Pennsylvania Working Papers in Linguistics

Volume 23

Issue 2 Selected Papers from New Ways of

Analyzing Variation (NWAV 45)

$11-2017$

\title{
It's No Problem to Be Polite: Apparent-Time Change in Responses to Thanks
}

Aaron J. Dinkin

San Diego State University

Follow this and additional works at: https://repository.upenn.edu/pwpl

\section{Recommended Citation}

Dinkin, Aaron J. (2017) "It's No Problem to Be Polite: Apparent-Time Change in Responses to Thanks," University of Pennsylvania Working Papers in Linguistics: Vol. 23 : Iss. 2 , Article 8.

Available at: https://repository.upenn.edu/pwpl/vol23/iss2/8

This paper is posted at ScholarlyCommons. https://repository.upenn.edu/pwpl/vol23/iss2/8

For more information, please contact repository@pobox.upenn.edu. 


\title{
It's No Problem to Be Polite: Apparent-Time Change in Responses to Thanks
}

\begin{abstract}
This paper reports a rapid and anonymous study of apparent-time change in progress among the use of variants such as you're welcome and no problem as responses to thanks. Data was collected by undergraduate students in Toronto as an assignment for an introductory sociolinguistics class; students asked passers-by and local business employees for directions to nearby locations, thanked them for their help by means of one of three thanking expressions of varying degrees of elaborateness (thanks, thank you, thank you very much), and noted the responses to the thanks. We observe change in progress toward no problem, with a significant interaction between age and the degree of elaborateness of the thanks expression. For younger speakers, thanks, thank you, and thank you very much all have about the same effect, each eliciting no problem around $40 \%$ of the time. For older speakers, no problem is used as a response to thanks but is strongly disfavored by the more elaborate expressions. This interaction may explain the intensity of the negative attention no problem attracts from prescriptivists and in popular media: older speakers appear to use no problem as a less polite variant than you're welcome, suitable principally as a response to more perfunctory expressions of thanks; younger speakers have no such restriction. The change in progress, therefore, is not merely a change in the frequency of one variant over another, but a functional change in the level of politeness associated with the variant; no problem is changing from perfunctory to polite as a response to thanks.
\end{abstract}




\title{
It's No Problem to Be Polite: Apparent-Time Change in Responses to Thanks
}

\author{
Aaron J. Dinkin*
}

\section{Introduction}

There is robust variation in how English speakers respond to being thanked: you're welcome, no problem, anytime, my pleasure, and a broad range of other variants are attested as available responses to thank you in multiple English-speaking communities. This variation is the subject of substantial popular commentary from prescriptivists and ostensible etiquette authorities, and such commentators often focus especially on condemning one variant in particular: no problem. A simple Google search turns up multiple articles and blog posts with titles asserting that "no problem is a problem" (e.g., Blasingame 2014; Flanagan 2013), and the content of these articles condemns the use of no problem in no uncertain terms. Remarks such as "it feels like a culturally significant obliteration of the difference between giving and demanding, expressing gratitude and saying sorry" (Noë 2015) are typical, attacking no problem both on the grounds of supposed unpleasantness and as an erosion of civilized norms.

The online discourse around no problem also perceives it as an innovation, or characteristic of young people, in comparison to other thanks responses such as you're welcome: Noë (2015) describes no problem as "a fairly recent change", and Flanagan (2013) attributes it to "everyone born after 1980". The belief that no problem is an innovation is not restricted to prescriptivists who complain about it; a widely-shared 2015 post on the Tumblr blog Absolutely No Sequins Whatsoever claims that the choice of thanks responses "clearly separates Baby Boomers from Millennials", and in particular suggests that "you're welcome' means to Millennials what 'no problem' means to Baby Boomers, and vice versa."

Surprisingly little sociolinguistic research on this variable has been conducted; the existing literature on responses to thanks resides principally within the research paradigm of interactional pragmatics, rather than variationist sociolinguistics. There are a handful of studies in this literature that engage empirical data quantitatively, using methodologies including written questionnaires (Schneider 2005; Mulo Farenkia 2012), recording interactions in a natural setting (Rüegg 2014), and rapid and anonymous studies (Bieswanger 2015); but none of them examine the question of whether change is in progress. For example, Bieswanger's methodology renders virtually any sociolinguistic analysis impossible by deliberately only collecting data from white speakers "between 30 and 50 years of age... and dressed in what could best be described as "business casual"" attire (2015:536), and Bieswanger attributes differences between his results and those of Schneider (2005) to their differences in methodology, without noting the potential relevance of the fact that Schneider collected data from substantially younger speakers.

Thus, despite a seemingly widespread popular perception that the system of responses to thanks is undergoing change toward no problem, none of the existing empirical studies of this variable of which I am aware have made an attempt to test this claim. The goal of this paper is to fill that gap and verify the hypothesis, in at least one speech community.

\section{Methodology}

\subsection{Data Collection and Compilation}

The data reported in this paper was collected by undergraduates at the University of Toronto as an assignment for Linguistics 351, "Sociolinguistic Patterns", an introductory/intermediate class in the theory and methodology of variationist sociolinguistics. During three academic terms (fall 2013, winter 2015, and summer 2015), after reading Labov (1972)'s foundational rapid and anon-

*Thanks to Matt Hunt Gardner, Marisa Brook, and Paulina Łyskawa, teaching assistants for Linguistics 351 at the University of Toronto, who assisted in coding and organizing the data. Thanks especially to Matt Hunt Gardner, who suggested responses to thanks as a possible topic for a class assignment. 
ymous New York department store study, students in Linguistics 351 were assigned to carry out a rapid anonymous study of variation in responses to thanks. Durian, Papke and Sampson (2009) discuss some of the pedagogical benefits of a rapid and anonymous study as an assignment in an introductory sociolinguistics class, and Ellis, Groff and Mead (2006) have previously published research based on data collected via such an assignment.

Students were instructed to ask for directions to nearby landmarks from passers-by or local business employees in various parts of Toronto. On being given directions, students were to respond with "thanks," "thank you," or "thank you very much," and note how their interlocutors responded. Each student was expected to conduct at least 20 elicitations in this way. Across the three semesters in which this project was assigned, a total of 1537 such elicitations were conducted, as shown in Table 1.

\begin{tabular}{lll}
\hline semester & number of students & number of elicitations \\
\hline Fall 2013 & 34 & 734 \\
Winter 2015 & 30 & 603 \\
Summer 2015 & 10 & 200 \\
\hline total & 74 & 1537 \\
\hline
\end{tabular}

Table 1. Total number of rapid anonymous elicitations of thanks responses conducted in the three terms in which this project was assigned.

In 2013, students entered their data in spreadsheets and submitted them online, after which they were compiled into a single file, checked for errors, and lightly recoded for clarity by teaching assistants and/or me. In 2015, to streamline the process and reduce the likelihood of errors in data entry, instead of spreadsheet files students submitted their data via a Google form set up for this purpose; see MacKenzie (to appear) on the benefits of this methodology. Depending on the exigencies of the academic calendar, students were given between one and two weeks to collect and submit their data in order to receive credit for the assignment.

\subsection{Dependent Variable}

The dependent variable in this study is the speaker's choice of response to being thanked. Students were asked to code this by selecting one from a short list of what Schneider (2005) calls "realization types", and then, in the event that the speaker had produced something other than the canonical form of that reaction type, to note exactly what they had said in a separate data-entry field (labeled "subvariant"). For example, if a speaker said no problem, the student would select the realization type NO PROBLEM and leave the subvariant field blank; if a speaker said no prob or no problemo, the student would select NO PROBLEM and transcribe the exact utterance in the subvariant field. For the purposes of the current analysis, we will consider three major realization types, each with more than 100 tokens in the data: YOU'RE WELCOME, NO PROBLEM, and NO WORRIES. In each case the canonical form (you're welcome, no problem, no worries) accounted for more than $90 \%$ of the tokens of the realization type. ${ }^{1}$

Responses other than YOU'RE WELCOME, NO PROBLEM, and NO WORRIES will be grouped into two categories: ACKNOWLEDGEMENT and OTHER. Although the primary pragmatic purpose of a response to thanks is to "minimize the thanker's indebtedness" (Schneider 2005:103), Bieswanger (2015:530-531) notes that not all responses to thanks actually appear to have that effect. Responding to thanks with an utterance like yeah or $u h-h u h$ serves to acknowledge that the thanker has spoken, but such responses "do not reduce the indebtedness of the thanker to 'the lowest possible level" "and would be equally appropriate in interactions in which no favor had been granted or thanks offered. The category of ACKNOWLEDGEMENT ${ }^{2}$ will be used to group together this class of

\footnotetext{
${ }^{1}$ This assumes that students remembered to transcribe the subvariant whenever one was produced, so that tokens with no transcribed subvariant can be taken to represent the canonical form. To avoid depending too heavily on this assumption, the analysis in this paper will focus on the realization types, rather than on the choice of subvariants.

${ }^{2}$ Students coded this under the heading of the realization type UH-HUH, but once the range of variants in
} 
responses. Subsumed into ACKNOWLEDGEMENT will be valedictions such as bye and have a nice day that conclude the interaction but similarly do not directly have the function of resolving the thanker's social indebtedness; this category occurs too infrequently to be given independent treatment. In some cases an acknowledgement cooccurred with another response, as in okay you're welcome; in such cases, the response was coded according to the type of the nonacknowledgement portion of the response.

Responses other than YOU'RE WELCOME, NO PROBLEM, and NO WORRIES that $d o$ (or arguably do) overtly have the pragmatic role of thanks responses, such as don't mention it, anytime, and it's nothing, will be grouped under the category OTHER. For conciseness, we may refer to the classes of YOU'RE WELCOME, NO PROBLEM, NO WORRIES, and OTHER, the response types that have the pragmatic role of reducing indebtedness, as the "proper" thanks responses.

Alongside YOU'RE WELCOME, NO PROBLEM, NO WORRIES, ACKNOWLEDGEMENT, and OTHER, the sixth value of the dependent variable in this analysis will be NO RESPONSE, including all individuals who gave no spoken response at all to being thanked. Some produced non-verbal responses such as smiling and nodding, but students were not asked to systematically record nonverbal responses and so they cannot be analyzed in this paper.

\subsection{Independent Variables}

Students were instructed to code their data for several independent variables as predictors of choice of response. In this paper, we will focus on two: the speaker's apparent age, ${ }^{3}$ and the prompt used for elicitation (thanks, thank you, or thank you very much).

Age is the key predictor for an investigation of change in apparent time. The choice of prompt can be used as a proxy for what may be interpreted as style, or level of politeness. Okamoto \& Robinson (1997) consider more elaborate thanking expressions, such as thank you very much, to be more polite than thank you, and the less elaborate thanks as less polite. In this study, it is hypothesized that a more elaborate thanking expression will in turn be more likely to elicit more polite responses to thanks, and thus this predictor can be used to diagnose whether one response is treated as more polite than another.

Other independent variables coded by students include each speaker's apparent gender, ethnicity, status as a native or non-native speaker of English, and status as a "passer-by" or local business employee when addressed by the student. These factors, plus the semester in which data was collected, were included in the multiple logistic regression models calculated below, but for the sake of brevity will be omitted from the discussion.

Due to the nature of this study, obviously the reliability of the results depends on our faith in the ability of 74 undergraduate students to approach a representative sample of speakers, to reasonably accurately guess the age, ethnicity, etc. of strangers, and to reliably and consistently code their results as instructed. The key results to be presented below are robust enough that it at least seems likely that they represent something real in the speech community, albeit passed through the noisy filter of a homework assignment in an introductory class.

\section{Results}

\subsection{Overall Distributional Results}

The overall breakdown of the response categories is shown in Table 2. YOU'RE WELCOME was the most frequently occurring response type overall, at about one third of elicitations; the second most common was NO PROBLEM, at about one quarter. The third most common response type was NO

this category became apparent, substantial recoding was necessary to ensure consistency. For the current analysis, some tokens that students had coded as OTHER have been moved into ACKNOWLEDGEMENT on the basis of their subvariant transcription, and vice versa.

${ }^{3}$ Students were asked to round their estimate to the nearest five years. Most of them remembered to do this, but some gave more precise estimates. In regression analyses in this paper, with age as a continuous factor, each student's estimate will be used at face value, even if not rounded. In binned reporting of age effects, all ages will be rounded. 
RESPONSE at all.

Figure 1 shows the frequency of each response type broken down by age group. It is clear from Figure 1 that NO PROBLEM is increasing in apparent time. For the three youngest age groups, NO PROBLEM is the most frequent response type, occurring for over $30 \%$ of elicitations; in the four oldest age groups, NO PROBLEM is below 10\%; in between, the rate of NO PROBLEM increases monotonically. YOU'RE WELCOME, although the most frequent response type overall, similarly shows a noticeable decrease in apparent time, diminishing to less than $25 \%$ in the youngest two age groups. So the basic apparent-time claim seen in popular discussion of this variable, that of change toward NO PROBLEM, is supported at least by the raw distribution of the data.

\begin{tabular}{lll}
\hline \multicolumn{1}{c}{ response type } & $n$ & frequency \\
\hline YOU'RE WELCOME & 514 & $33 \%$ \\
NO PROBLEM & 385 & $25 \%$ \\
NO RESPONSE & 281 & $18 \%$ \\
ACKNOWLEDGEMENT & 172 & $11 \%$ \\
NO WORRIES & 123 & $8 \%$ \\
OTHER & 62 & $4 \%$ \\
\hline
\end{tabular}

Table 2. Total number of elicitations of each of the six response types, out of $n=1537$ elicitations.

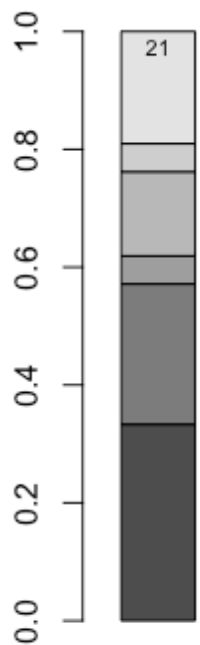

15

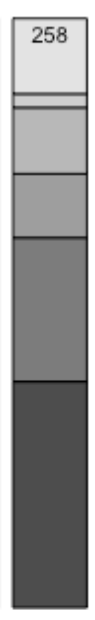

20

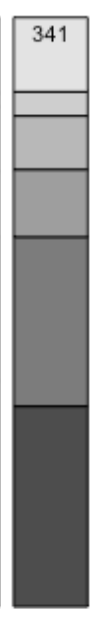

25

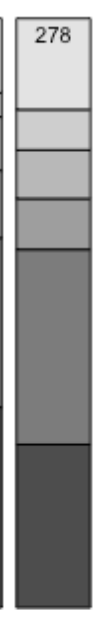

30

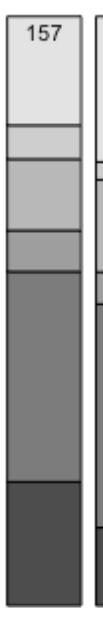

$35 \quad 40$

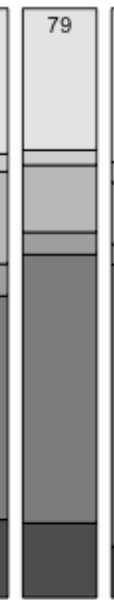

45

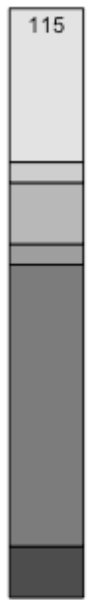

50
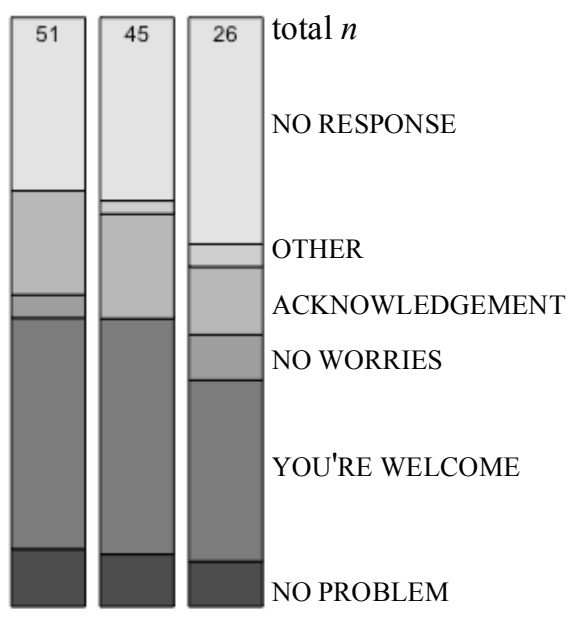

$60 \quad 65+$

Age group

Figure 1. Distribution of the six response categories by age group.

Figure 1 also demonstrates another unexpected pattern by age: older speakers are much more likely to give NO RESPONSE than younger speakers. The oldest age group gave NO RESPONSE to being thanked fully $38 \%$ of the time, more than any other response type; and the rate of NO RESPONSE decreases almost monotonically with age down to only $13 \%$ in the 20 - and 25 -year-old groups. If this were to be interpreted through the apparent-time model, it would seem to imply that, contrary to the expectations of worried prescriptivists, the Toronto speech community is becoming more polite over time-i.e., more likely to give a spoken response of some kind when thanked, rather than just ignoring the thanker. It seems unlikely to me that apparent-time change is the actual reason for this age effect, however; more probably, it may represent a sort of age-solidarity effect. The data collectors, being undergraduate students in a third-year class, were mostly in the 2025 age range themselves; perhaps people are more likely to respond relatively politely to a thanker of their own age than one several decades younger. 


\subsection{Regression Models}

In order to conduct an accountable quantitative analysis of this variable, modeling how stylistic and social factors influence the speaker's choice of response type, it is necessary to have a theory of what choices the speaker is making: what variants is the speaker is choosing between at any given point? When a speaker chooses to say no problem, are they thereby rejecting you're welcome; or by the time no problem is an option on the table has you're welcome already been rejected long ago? For the purposes of this analysis, we will assume the following structure of variation: When a speaker is thanked, we hypothesize that the first choice they must make is whether or not to respond at all; if they decide to respond, we hypothesize that the next choice is between giving a mere ACKNOWLEDGEMENT and giving a proper thanks response. Thus, when considering the factors affecting the choice to give NO RESPONSE, we will perform binomial regressions on the choice between NO RESPONSE and all other response types; but when considering the factors favoring or disfavoring ACKNOWLEDGEMENT, the NO RESPONSE category will be excluded from the analysis and ACKNOWLEDGEMENT will only be considered in opposition to the other spoken responses. There does not appear to be a strong a-priori motivation for assuming one hierarchy or another among the four types of proper thanks responses; therefore analyses focusing on those will compare each of those types against all the others (but exclude ACKNOWLEDGEMENT and NO RESPONSE).

Binomial logistic regression models for this data are calculated using Rbrul (see Johnson 2009). Attempts to compute mixed-effect models failed to converge and therefore failed to produce reliable results; therefore results from fixed-effects-only models will be reported below. In order to make regression coefficients easier to interpret, the age variable included in the regressions is speaker age minus 33, the approximate mean age of all speakers in the data.

We begin with NO RESPONSE. There is a statistically significant interaction between age and thanking prompt as predictors of NO RESPONSE, as shown in Table 3 and illustrated in Figure 2.

\begin{tabular}{llrr}
\hline predictor & value & log-odds & $n$ \\
\hline \hline age $\times$ prompt & thanks $\times 1$ year & +0.023 & 439 \\
& thank you $\times 1$ year & +0.006 & 796 \\
\cline { 2 - 4 } & thank you very much $\times 1$ year & -0.029 & 302 \\
\hline prompt main effect & thanks & +0.214 & 439 \\
& thank you & +0.020 & 796 \\
\cline { 2 - 4 } & thank you very much & -0.234 & 302 \\
\hline age main effect & +1 year & +0.029 & 1537 \\
\hline
\end{tabular}

Table 3. Significant interaction $(p \approx 0.01)$ of age and prompt as predictors of NO RESPONSE vs. all spoken responses. Intercept $=-1.365$.

The main effects of age and thanking prompt are exactly as expected. Older speakers are more likely to give NO RESPONSE than younger speakers, this was shown above in Figure 1. The effect of prompt supports the hypothesis that the different prompts can be used to elicit different levels of politeness: the more elaborate the thanking expression, the more likely it is to be acknowledged with a spoken response. However, the interaction between these two predictors complicates the analysis somewhat: the difference between the effects of different thanking prompts is only present for older speakers. One possible interpretation of this result (of which prescriptivists would no doubt approve) is that younger speakers are not sensitive to the difference in politeness between thanks, thank you, and thank you very much, and therefore don't distinguish between them in deciding how to respond; however, we will see below that this interpretation in its strong form is unlikely to be right. It seems more likely that degree of politeness of the thanking expression modulates the age solidarity effect; i.e., it takes both a lack of age solidarity and a low level of politeness of the thanks expression to increase the rate of NO RESPONSE.

ACKNOWLEDGEMENT shows age and prompt effects in the same direction as NO RESPONSE, as shown in Table 4, though they do not have a statistically significant interaction. To the extent that ACKNOWLEDGEMENT is less polite than a proper thanks response, in the same way that NO RE- 
SPONSE is less polite than responding, this parallelism is expected.

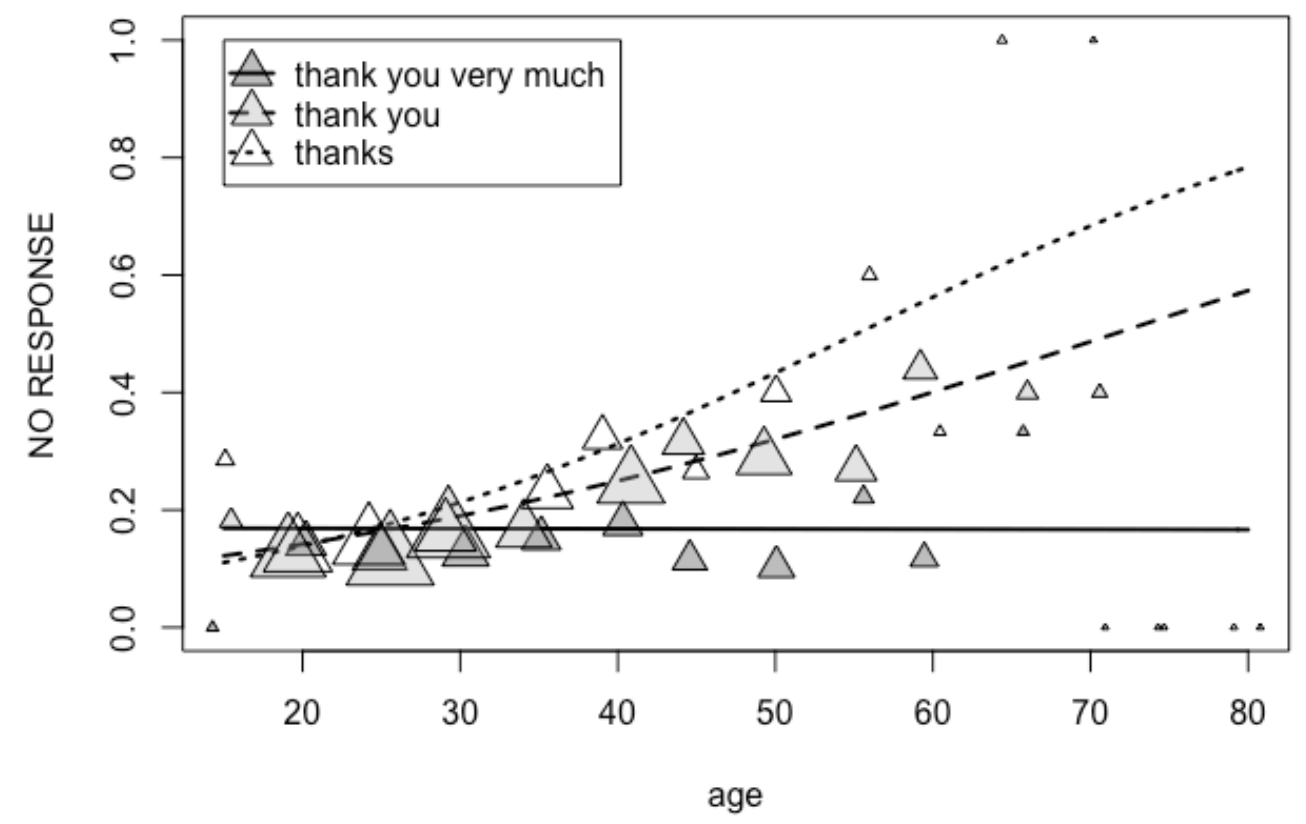

Figure 2. The interaction of age with thanking prompt as a predictor of NO RESPONSE. Lines represent the rates of NO RESPONSE predicted by the regression model in Table 3; triangles represent the actual rates of NO RESPONSE in the data by age group and prompt. Area of triangles is proportional to number of tokens, with the size appearing in the legend equivalent to 36 tokens.

\begin{tabular}{llrr}
\hline predictor & value & log-odds & $n$ \\
\hline \hline \multirow{2}{*}{ prompt } & thanks & +0.388 & 352 \\
\cline { 2 - 4 } & thank you & +0.048 & 643 \\
\cline { 2 - 4 } & thank you very much & -0.436 & 261 \\
\hline age & +1 year & +0.030 & 1256 \\
\hline
\end{tabular}

Table 4. Effects of age and prompt $(p<0.01)$ as predictors of ACKNOWLEDGEMENT vs. all proper thanks responses. Intercept $=-2.197$.

\begin{tabular}{llrr}
\hline predictor & value & log-odds & $n$ \\
\hline \hline \multirow{2}{*}{ age $\times$ prompt } & thanks $\times 1$ year & +0.034 & 292 \\
\cline { 2 - 4 } & thank you very much $\times 1$ year & -0.013 & 238 \\
\cline { 2 - 4 } & thank you $\times 1$ year & -0.021 & 554 \\
\hline prompt main effect & thanks & +0.331 & 292 \\
\cline { 2 - 4 } & thank you very much & -0.088 & 238 \\
\cline { 2 - 4 } & thank you & -0.242 & 554 \\
\hline age main effect & +1 year & -0.050 & 1084 \\
\hline
\end{tabular}

Table 5. Significant interaction $(p \approx 0.01)$ of age and prompt as predictors of NO PROBLEM vs. other proper thanks responses. Intercept $=-0.793$.

NO PROBLEM also exhibits an interaction between age and prompt, as shown in Table 5 and Figure 3. As inferred from Figure 1 above, NO PROBLEM is favored by younger speakers, supporting the hypothesis of apparent-time change toward NO PROBLEM that motivated this paper. However, although NO PROBLEM is increasing in apparent time as a response to all three prompts, the slope of increase is much shallower for thanks than for thank you and thank you very much. Thus 
younger speakers use NO PROBLEM at similar rates with all three prompts, while older speakers use NO PROBLEM at a much higher rate as a response to thanks than to the more elaborate thanking expressions. This suggests that, at least for older speakers, NO PROBLEM is regarded as a less polite response, suitable for responding to a briefer and more perfunctory expression of thanks but not to a more polite thanking prompt. The fact that thank you very much and thank you converge with thanks in Figure 6 for the younger speakers is evidence in favor of the straw-man hypothesis introduced above that younger speakers are simply not sensitive to the difference in politeness between thanks, thank you, and thank you very much; however, examining the other proper thanks responses will contradict this hypothesis.

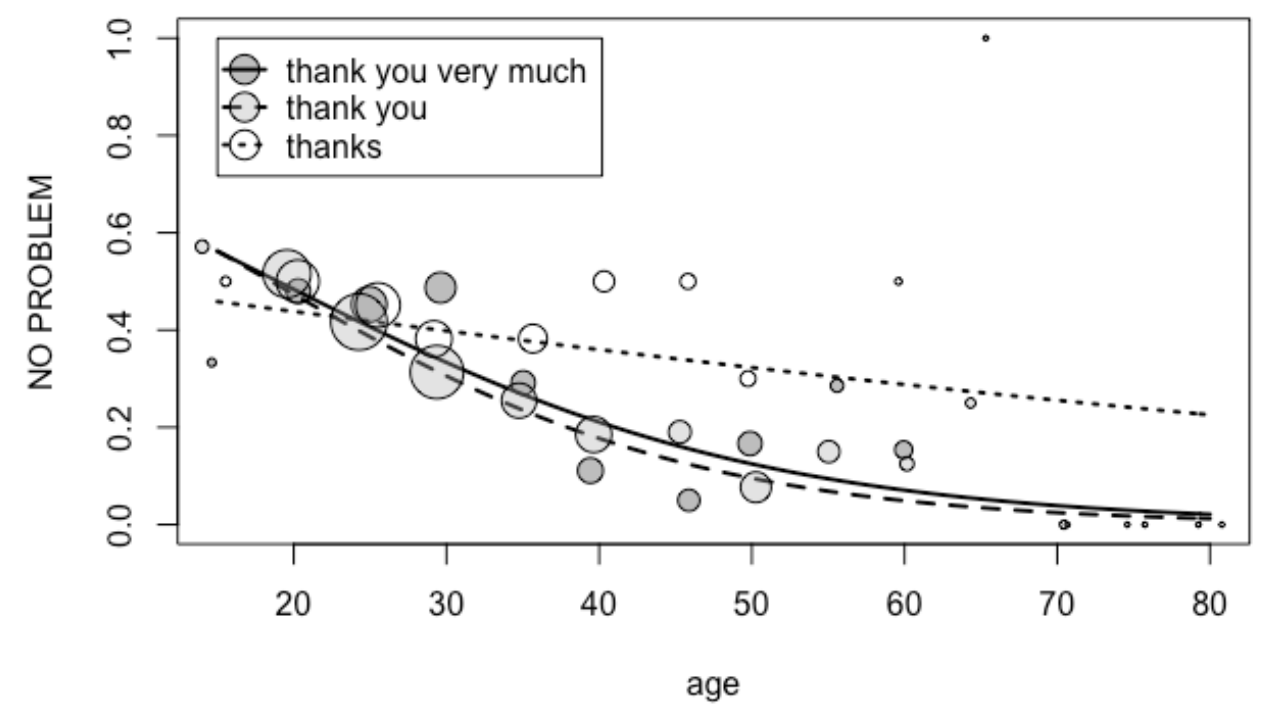

Figure 3. The interaction of age with thanking prompt as a predictor of NO PROBLEM.

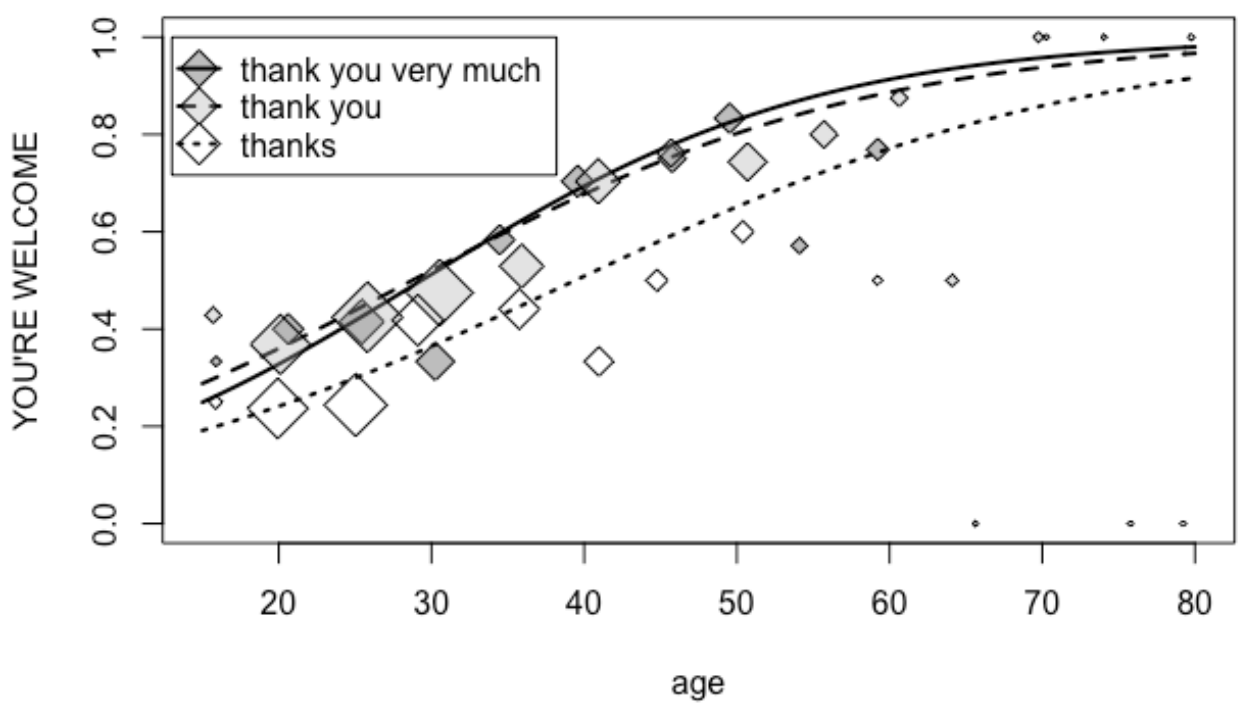

Figure 4. The lack of significant interaction between age and thanking prompt as predictors of YOU'RE WELCOME. Due to non-significance, this interaction is excluded from the model reported in Table 6; the log-odds slopes of the three curves in this figure are +0.077 (thank you very much), +0.066 (thank you), and +0.059 (thanks).

The principal competitor of NO PROBLEM is YOU'RE WELCOME, and so it is unsurprising that the main effects of age and prompt on YOU'RE WELCOME, shown in Table 6, are the opposite of 
those for NO PROBLEM: YOU'RE WELCOME is declining in apparent time and favored by more polite thanking expressions. However, unlike NO PROBLEM, YOU'RE WELCOME exhibits no significant interaction between these predictors. As Figure 4 illustrates, the difference between thanks on the one hand and thank you and thank you very much on the other as elicitors of YOU'RE WELCOME remains robust even among the youngest speakers. When the data is restricted to only the youngest four age groups, prompt remains one of the strongest predictors of YOU'RE WELCOME, with a log-odds difference of 0.59 between thank you and thanks. Thus, unlike NO PROBLEM, YOU'RE WELCOME shows that younger speakers do differentiate between the politeness levels of different thanking expressions.

\begin{tabular}{llrc}
\hline predictor & value & log-odds & $n$ \\
\hline \hline \multirow{2}{*}{ prompt } & thank you very much & +0.214 & 238 \\
& thank you & +0.207 & 554 \\
\cline { 2 - 4 } & thanks & -0.421 & 292 \\
\hline age & +1 year & +0.067 & 1084 \\
\hline
\end{tabular}

Table 6. Effects of age and prompt $(p<0.0005$ ) as predictors of YOU'RE WELCOME vs. all other proper thanks responses. Intercept $=+0.076$.

\begin{tabular}{llrc}
\hline predictor & value & log-odds & $n$ \\
\hline \hline \multirow{2}{*}{ prompt } & thanks & +0.614 & 292 \\
\cline { 2 - 4 } & thank you & -0.245 & 554 \\
\cline { 2 - 4 } & thank you very much & -0.369 & 238 \\
\hline age & +1 year & -0.039 & 1084 \\
\hline
\end{tabular}

Table 7. Effects of age and prompt $(p<0.05)$ as predictors of NO WORRIES vs. all other proper thanks responses. Intercept $=-2.229$.

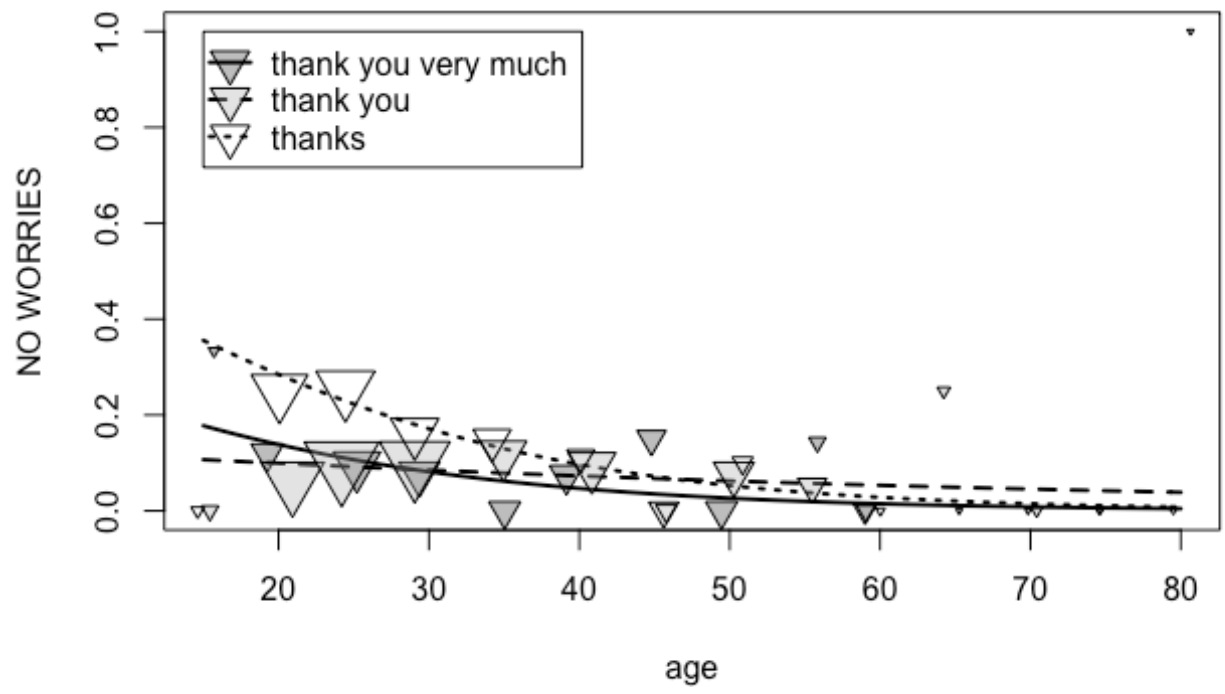

Figure 5. Age and thanking prompt as predictors of NO WORRIES. The log-odds slopes for the three curves in this figure are -0.059 (thank you very much), -0.017 (thank you), and -0.065 (thanks); the difference between slopes does not reach the level of statistical significance $(p \approx 0.075)$.

This is also reflected in NO WORRIES, the third moderately frequent realization type. Table 7 shows that, like NO PROBLEM, NO WORRIES is increasing in apparent time and favored by thanks. However, unlike NO PROBLEM, the conditioning effect of prompt does not disappear for the youngest speakers. Indeed, it is only among the youngest speakers that the frequency of NO WORRIES 
becomes high enough for any difference between thanks on the one hand and thank you and thank you very much on the other hand to become visible, as shown in Figure 5. When the data is restricted to the youngest four age groups, prompt is the only significant predictor of NO WORRIES, with a log-odds difference of 1.13 between thanks and thank you.

\section{Discussion}

Despite the patterns visible in Figures 2 and 3, it is not the case that younger speakers simply do not distinguish between the politeness levels of thanks, thank you, and thank you very much. Younger speakers appear to use NO WORRIES as a less polite response, more suitable for responding to thanks than to a more elaborate expression such as thank you very much, and use YOU'RE WELCOME as a more polite response that receives the opposite treatment. The fact that younger speakers do not differentiate between thanking prompts in their rate of use of NO PROBLEM is therefore a fact about NO PROBLEM in particular, not about how young speakers respond to thanks in general. This suggests that NO PROBLEM specifically is undergoing a change in its level of politeness. For older speakers, NO PROBLEM appears to function as a perfunctory or less polite response, suitable for thanks but not thank you or thank you very much; but for younger speakers, it is in the process of migrating toward the category of more polite responses, appearing at similar rates in response to all three thanking expressions.

As NO PROBLEM loses its less-polite character for younger speakers, the incipient response type NO WORRIES appears to be taking on that role. The pragmatics literature on responses to thanks classifies responses according to how they accomplish the pragmatic task of minimizing the thanker's indebtedness; NO WORRIES and NO PROBLEM are both within the class of "minimizing the favor" (see e.g. Schneider 2005). ${ }^{4}$ These two response types are both increasing in apparent time relative to other proper thanks responses, while one is taking over the former stylistic role of the other. Meanwhile, YOU'RE WELCOME's stylistic conditioning remains roughly constant. This suggests that there may be two distinct changes affecting the domain of proper thanks responses: the class of responses that "minimize the favor" is gaining ground in apparent time at the expense of other response types; and within that class, the once-marginal response type NO WORRIES is establishing itself as an informal variant, allowing NO PROBLEM to increase its relative frequency in more polite contexts. This hypothesis would predict that other "minimizing the favor" variants, such as it's nothing and it's okay, might also be increasing in apparent time as a fraction of all thanks responses; however, variants such as these are very marginal in the data (11 and 9 tokens, respectively), and so it is difficult to determine at this time whether the rising tide of NO PROBLEM and NO WORRIES is lifting these boats as well.

These results suggest a potential explanation for the intensity of the prescriptive condemnation of no problem: it's not just the frequency of use of NO PROBLEM that is increasing in apparent time, but its level of politeness. This means that older speakers hear younger speakers responding with NO PROBLEM to more elaborate thanks expressions such as thank you very much at what appears to be a disproportionately high frequency. They perceive that as the use of an informal response in contexts in which a more formal response is called for, and therefore interpret it as young people ignoring norms of politness. From the younger speakers' perspective, however, NO PROBLEM has simply joined the category of sufficiently polite responses.

\section{Conclusion}

The study reported in this paper investigates change in progress in responses to thanks, a question that is seemingly completely neglected in prior research on this variable. The results corroborate the popular perception of change in progress toward no problem and away from you're welcome, and demonstrate that this is chiefly (but not entirely) due to younger speakers being more willing than older speakers to use NO PROBLEM in response to a more elaborate or polite prompt. Thus it is not only the frequency of use of NO PROBLEM that is undergoing change, but also its stylistic function.

\footnotetext{
${ }^{4}$ By contrast, YOU'RE WELCOME is in the class of "expressing appreciation for the addressee".
} 
Previous empirical research (e.g., Mulo Farenkia 2012) has found indications that the identity of the thanker and the type of favor being thanked for can also affect the choice of thanks response; and Schneider (2005) and Bieswanger (2015) found differences in the rates of NO PROBLEM, YOU'RE WELCOME, and other response types between different speech communities. More in-depth and accountable analyses of the effects of these sources of variability seem likely to be productive directions for future variationist work on this topic.

The rapid and anonymous study is an effective pedagogical tool for introducing beginning students to sociolinguistic methodology, and responses to thanks have proven to be an ideal variable to serve as a topic for such an assignment - thanks responses are simple to elicit, easily identifiable, and robustly variable. I encourage other instructors of introductory sociolinguistics to consider reproducing this study, or expanding upon it, as an assignment in their own classes. If they do, these outstanding research questions on thanks responses will be able to be answered quickly indeed.

\section{References}

Absolutely No Sequins Whatsoever. 2015, July 7. Speaking of linguistics, there's... [Tumblr post]. URL http: //thisisnotharmless.tumblr.com/post/123515417343/speaking-oflinguistics-theres-one-particular. Viewed 24 February 2017.

Bieswanger, Markus. 2015. Variational pragmatics and responding to thanks - revisited. Multilingua 34.4:527-546.

Blasingame, Jim. 2014. "Thank you" is golden, "no problem" is a problem. Forbes. URL http: / /www. forbes.com/sites/jimblasingame/2014/07/25/thank-you-isgolden-no-problem-is-a-problem. Viewed 17 October 2016.

Durian, David, Julia Porter Papke, and Salena Sampson. 2009. Exploring social, regional, and ethnic variation in the undergraduate classroom. American Speech 84:227-238.

Ellis, Michael, Cynthia Groff, and Rebecca Mead. 2006. A rapid and anonymous study of /r/vocalization in an /r/ pronouncing city. University of Pennsylvania Working Papers in Linguistics 12.1, ed. by A. Eliam, T. Scheffeler, and J. Tauberer.

Flanagan, Bill. 2013. "No problem": Yes, it's a BIG problem. CBS News. URL http: //www.cbsnews.com/news/no-problem-yes-its-a-big-problem. Viewed 17 October 2016.

Johnson, Daniel Ezra. 2009. Getting off the GoldVarb standard: Introducing Rbrul for mixed-effects variable rule analysis. Language and Linguistics Compass 3.1:359-383.

Labov, William. 1972. The social stratification of (r) in New York City department stores. In Sociolinguistic Patterns, W. Labov, 43-54. Philadelphia: University of Pennsylvania Press.

MacKenzie, Laurel. To appear. Dialect surveys and student-led data collection. In Data Collection in Sociolinguistics: Methods and Applications, Second Edition, ed. C. Mallinson, B. Childs, and G. Van Herk. New York: Routledge

Mulo Farenkia, Bernard. 2012. Face-saving strategies in response to gratitude expressions: Evidence from Canadian English. International Journal of English Linguistics 2.4:1-11.

Noë, Alva. 2015. A case against the phrase "no problem". Blog post at 13.7: Cosmos \& Culture. URL http://www.npr.org/sections/13.7/2015/02/01/383060338. Viewed 17 October 2016.

Okamoto, Shinichiro, and W. Peter Robinson. 1997. Determinants of gratitude expressions in England. Journal of Language and Social Psychology 16.4:411-433.

Rüegg, Larssyn. 2014. Thanks responses in three socio-economic settings: A variational pragmatics approach. Journal of Pragmatics 71:17-30.

Schneider, Klaus P. 2005. "No problem, you're welcome, anytime": Responding to thanks in Ireland, England, and the U.S.A. In The Pragmatics of Irish English, ed. by A. Barron \& K. P. Schneider, 101-139. Berlin: Mouton de Gruyter.

Department of Linguistics and Asian/Middle Eastern Languages

San Diego State University

San Diego CA 92182-7727

ajd@post.harvard.edu 